\title{
Pacifiers have greater analgesic effect than sweet solutions during venipuncture in full term newborns
}

Carbajal R, Chauvet X, Couderc S, et al.Randomised trial of analgesic effects of sucrose, glucose, and pacifiers in term neonates. BMJ 1999 Nov 27;319:1393-7.

QUESTION: In full term newborns having venipuncture, what are the analgesic effects of glucose, sucrose, and pacifiers?

Design

Randomised (allocation concealed*), blinded (outcome assessor was blinded to type of solution but not to the pacifier),* placebo controlled trial.

\section{Setting}

Maternity ward of a hospital in Poissy, France.

\section{Patients}

150 eligible newborns ( $59 \%$ boys) who had a 5 minute Apgar score $\geq 7$, were medically stable, had not received naloxone during the previous 24 hours, and were not fed in the previous 30 minutes. 50 eligible newborns were not randomised because of non-availability of the observer (investigator).

\section{Intervention}

Infants were allocated to 1 of 6 groups with 25 infants each: no treatment, placebo (2 $\mathrm{ml}$ of sterile water), $2 \mathrm{ml}$ of $30 \%$ glucose, $2 \mathrm{ml}$ of $30 \%$ sucrose, a pacifier, and $2 \mathrm{ml}$ of $30 \%$ sucrose and a pacifier. The solutions or pacifiers were given 2 minutes before venipuncture.

\section{Main outcome measure}

Pain during venipuncture and blood collection using the Douleur Aiguë du Nouveau-né (DAN) scale, a pain score $(0=$ no pain, $10=$ maximum pain $)$ based on facial expression, limb movements, and vocal expression.

For correspondence: Dr R Carbajal,

Department of

Paediatrics, Poissy

Hospital, 78300 Poissy,

France. Fax +33139

274433

\section{Main results}

The groups receiving glucose, sucrose, pacifiers, and sucrose plus pacifier had lower pain scores than the placebo group $(p \leqslant 0.01)$ (table). The pacifier group had

Median pain scores during venipuncture for newborns using the Douleur Aiguë du Nouveau-né (DAN) scale

\begin{tabular}{lll} 
Comparison & $\begin{array}{l}\text { Median pain } \\
\text { scores }\end{array}$ & $\begin{array}{l}\text { Median difference } \\
(95 \% \mathrm{Cl})\end{array}$ \\
$30 \%$ glucose $v$ placebo & $5 v 7$ & $2(1$ to 4$)$ \\
\hline $30 \%$ sucrose $v$ placebo & $5 v 7$ & $2(0$ to 4$)$ \\
\hline Pacifier $v$ placebo & $2 v 7$ & $6(5$ to 7$)$ \\
\hline $30 \%$ sucrose + pacifier $v$ placebo & $1 v 7$ & $3(2$ to 5$)$ \\
\hline $30 \%$ glucose $v$ pacifier & $5 v 2$ & $3(1$ to 5$)$ \\
\hline $30 \%$ sucrose $v$ pacifier & $5 v 2$ & $1(0$ to 2$) \ddagger$ \\
\hline $30 \%$ sucrose + pacifier $v$ pacifier & $1 v 2$ & \\
\hline
\end{tabular}

†DAN scale pain score: $0=$ none, $10=$ maximum. $\mathrm{Cl}$ defined in glossary. $\ddagger$ Not significant.

lower pain scores than the glucose or sucrose groups $(p \leqslant 0.001)$; pacifier and sucrose plus pacifier groups did not differ $(\mathrm{p}=0.06)$ (table).

\section{Conclusions}

In newborns having venipuncture, use of glucose and sucrose solutions and pacifiers reduced pain. Pacifiers were more effective than sweet solutions.

*See glossary.

\section{COMMENTARY}

Effective measures to minimise pain and discomfort in newborn infants having procedures are of recognised importance. ${ }^{1}$ Carbajal et al compared "sweeteners" with pacifiers and placebo in newborn infants having venipuncture.

The investigators used a 10 point evaluation tool for measuring pain (facial expression, limb movements, and vocal expression) recently reported by the principal investigator to have high internal consistency and interrater agreement ${ }^{2}$; no demonstrated correlation with biochemical markers of stress exists. In this randomised controlled trial, the investigators recognise a potential bias with the use of pacifiers not being blinded. It is reassuring, however, that the differences between the pacifier and placebo groups were greater than those between the pacifier and sweet solutions groups.

Potential mechanisms of action of pacifiers (sensory dominance or facilitated self regulation) are addressed in the article's discussion. Efficacy in preterm infants and during such other procedures as heel lancing remains to be determined. While the use of pacifiers for newborn infants is often discouraged, this study shows that pacifiers are more effective than $30 \%$ glucose or $30 \%$ sucrose solutions, a finding that should stimulate clinical practice changes for newborn infants having venipuncture.

Douglas D McMillan, MD Calgary Regional Health Authority Calgary, Alberta, Canada

1 Prevention and management of pain and stress in the neonate. American Academy of Pediatrics. Committee on fetus and newborn. Committee on drugs. Section on anesthesiology. Section on surgery. Canadian Paediatric Society. Fetus and newborn committee. Pediatrics 2000;105:454-61.

2 Carbajal R, Paupe A, Hoenn E, et al. APN: evaluation behavioral scale of acute pain in newborn infants. Arch Pediatr 1997;4:623-8. 